\title{
Two New Records of Upeneus Spottocaudalis and $U$. Sundaicus (Perciformes: Mullidae) from the Northern South China Sea Based on the Morphology and DNA Barcoding
}

\author{
Zhisen Luo \\ Guangdong Ocean University \\ Murong Yi \\ Guangdong Ocean University \\ Kangwen Qiu \\ Guangdong Ocean University \\ Sibiao Liu \\ Guangdong Ocean University \\ Sui Gu \\ Guangdong Ocean University \\ Yunrong Yan ( $\nabla$ yryan_gdou@163.com ) \\ Guangdong Ocean University
}

\section{Research Article}

Keywords: Upeneus spottocaudalis, Upeneus sundaicus, South China Sea, new record, morphology, DNA barcode

Posted Date: September 16th, 2021

DOl: https://doi.org/10.21203/rs.3.rs-789149/v1

License: (c) (i) This work is licensed under a Creative Commons Attribution 4.0 International License. Read Full License 


\section{Abstract}

In this study, two new records of goatfishes Upeneus spottocaudalis and U. sundaicus from the South China Sea, combing evidence from morphology and DNA barcodes for species identification. ML tree and $\mathrm{NJ}$ tree result showed that the sequences of $U$. spottocaudalis and $U$. sundaicus were clustered with the homologous sequences form GenBank, respectively, and the intraspecific genetic distances of $U$. spottocaudalis $(0.2 \%)$ and U. sundaicus $(0.3 \%)$ were less than $2 \%$. Automatic Barcode Gap Discovery (ABGD) analysis also supported this result of classification.

\section{Main Text}

The genus of Upeneus (Perciformes: Mullidae) up to 46 goatfish species worldwide and widely distributed in tropical and subtropical ocean area (Uiblein and Gouws 2014; Nelson and Mark 2016; Uiblein and Motomura 2021). In China, the goatfishes species diversity were decreased with latitude, such as only one species $U$. japonicus was recorded in the Bohai Sea and the Huanghai Sea (Jiao and Chen 2000), including $U$. tragula, U. vittatus, U. subvittatus, $U$. sulphureus, $U$. quadrilineatus, $U$. moluccensis, $U$. japonicus, U. luzonius and U. heterospinus (Cheng et al. 1962; Shen 1993; Chen and Zhang 2015; Uiblein et al. 2019). Goatfishes sometimes are difficult to accurately identify based on the morphology method because the color patterns of different stages of development was unclear, and fading and discoloring of body color after death (Pavlov and Emel Yanova 2018). Using DNA barcoding technology can provide some level to reduce the difficulty of identification and enhance the accuracy of identification (Yi et al. 2018; Sharifuzzaman et al. 2021).

The South China Sea, as the most significant water area in China, possesses complex habitats to provide various marine organisms with a well living environment, leading to abundant biological resources in the South China Sea (Shan et al. 2021). However, an underestimated species diversity is not conducive to the protection of biodiversity and biological resources. Therefore, our study intends to close the knowledge gap by contributing to the taxonomy of the genus Upeneus in the South China Sea.

Specimens were collected from local fish markets near the northwestern South China Sea. Specimens and tissue samples were deposited at the College of Fisheries, Guangdong Ocean University (sampling sites see table S1). The counts and measurements were based on Uiblein and Heemastra (Uiblein and Heemstra 2010). COI gene was amplified by PCR using the two pairs universal primers from Ward et al. (Ward et al. 2005), and the PCR products were sequenced by Sangon Biotech (Shanghai). Thirty-three sequences were aligned and manually edited using Sequencher 5.4.5 (Gene Codes Corp., America). These sequences were deposited in GenBank (MZ513942-MZ513973 and MZ514010). Kimura 2-parameter $(\mathrm{K} 2 \mathrm{P})$ model was employed to construct the neighbour-joining $(\mathrm{NJ})$ tree and calculated the genetic distances by MEGA 6.0. The maximum likelihood (ML) tree was constructed using IQ-TREE (Nguyen et al. 2015) under the best-fit model, HKY +G4+F selecting BIC criterion by ModelFinder (Kalyaanamoorthy et al. 2017) for 5000 ultrafast bootstraps (Minh et al. 2013) and 1000 replicates of Shimodaira-Hasegawa test (SH-aLRT) (Guindon et al. 2010). The IQ-TREE and ModelFinder were plugins in PhyloSuite v1.2.2 (Zhang 
et al. 2020). All homologous sequences of Upeneus were from GenBank. Automatic Barcode Gap Discovery (ABGD) was carried out on the website with default parameter (https://bioinfo.mnhn.fr/abi/public/abgd/). Information of specimens and COI sequences are provided in Table S1.

Morphometric measurements of $U$. spottocaudalis and $U$. sundaicus was shown in Table 1. Upeneus spottocaudalis was firstly recorded in the southern Indonesia and the northeastern Australia (Uiblein et al. 2017), and Fricke (Fricke et al. 2019) found the distribution extended to the New Ireland. This species with VII spines in the first dorsal-fin are divided into japonicus-group; head and body dorsally reddish; midlateral body with a faint reddish band extending the upper base of caudal-fin; series red blotches on the body; barbels yellow; lower caudal-fin with rounded or triangular dark spots or blotches is the key taxonomic features to distinguish with other species of japonicus-group, which only are with oblique stripes in lower caudal-fin (Fig. 1a). Upeneus sundaicus with VIII spines in the first dorsal-fin belongs to tragula-group; head and body dorsally pale brown; a blonder brown stripe on the mid-lateral body from behind the upper operculum to the base of the caudal-fin; barbels yellow; lower caudal-fin without any spot or stripe; upper caudal-fin with series weak stripes (Fig. 1c).

The phylogenetic tree (Fig. 2) shows that our sequences of $U$. spottocaudalis were clustered with the sequence (GU673189) of paratype of $U$. spottocaudalis. Furthermore, the $U$. sundaicus sequences in this study of were clustered with the sequences identified as $U$. sundaicus from GenBank. These two results were also presented in the $\mathrm{NJ}$ tree. All of these clades were supported with high value of SH-aLRT, and ultrafast bootstrap. The intraspecific genetic distances of $U$. spottocaudalis $(0.2 \%)$ and $U$. sundaicus $(0.3 \%)$ were much less than $2 \%$ (Table S1). Result of classification based on ABGD was concordant with the $\mathrm{ML}$ tree and the $\mathrm{NJ}$ tree (Fig. 2).

Taxonomy is the most basic subject in biological studies, and accurate species identification determines the feasibility of subsequent studies. Two new records species of $U$. spottocaudalis and $U$. sundaicus were identified integrating morphology and DNA barcodes, which enrich the diversity of ichthyofauna of the South China Sea. It is of certain reference value to the taxonomy of the genus Upeneus in the South China Sea.

\section{Declarations}

Funding This study was funded by the National Key R\&D Program of China (Grant Number: 2018YFD0900905), Southern Marine Science and Engineering Guangdong Laboratory (Zhanjiang), (Zhanjiang Bay Laboratory) (Grant Number: ZJW-2019-08), Science and Technology Plan Projects of Guangdong Province, China (Grant Number: 2018B030320006), Guangdong Basic and Applied Basic Research Foundation (Grant Number: 2019B1515120064) and Special Project of Guangdong Provincial Marine Economy Development of China (Grant Number: GDNRC[2020]052).

Authors' contributions Zhisen Luo investigated, collected the specimens, conducted the experiments, finished the drawing, analyzed data, edited the original draft and reviewed the manuscript. Murong Yi, 
investigated, collected the specimens, provided the methodology, supervised the experiments, designed, reviewed and edited the manuscript, decided on the final manuscript. Kangwen Qiu assisted to the experiments, reviewed and edited the manuscript. Sibiao Liu analyzed data, reviewed and edited the manuscript. Sui Gu, supervised the experiments, reviewed and edited the manuscript. Yunrong Yan provided experimental conditions, supervised, reviewed and edited the manuscript.

Availability of data and material Information of COI sequences are available in the NCBI website (https://www.ncbi.nlm.nih.gov/). Information of collection of specimens of this study are provided in the Supplementary Table Captions. All measurement and analyzed data are presented in this manuscript. Automatic Barcode Gap Discovery (ABGD) analysis is conducted on the ABGD website (https://bioinfo.mnhn.fr/abi/public/abgd/).

Ethical Approval All animal experiments were carried out in accordance with the guidelines and approval of the Animal Research and Ethics Committee of College of Fisheries, Guangdong Ocean University (permissions, B20181030-01).

Consent to participate On behalf of all authors, consent to participate this manuscript writing and contribute to Conservation Genetics Resources.

Consent to publication On behalf of all authors, consent to publish this article.

\section{References}

1. Chen D, Zhang M (2015) Family Mullidae. In: Chen D, Zhang M (ed) Marine fishes of China. China Ocean University Press, Qingdao, pp 1254囚1267

2. Cheng Q, Wang C, Tian M, Yang W, Sun B (1962) Family Mullidae. In: Zhu YD (ed) Fishes of the South China Sea. Science Press, Beijing, pp 548ه563

3. Fricke R, Allen GR, Amon D, Andréfouët S, Chen W-J, Kinch J, Mana R, Russell BC, Tully D, White WT (2019) Checklist of the marine and estuarine fishes of New Ireland Province, Papua New Guinea, western Pacific Ocean, with 810 new records. Zootaxa 4588(1):1®360

4. Guindon S, Dufayard J-F, Lefort V, Anisimova M, Hordijk W, Gascuel O (2010) New algorithms and methods to estimate maximum-likelihood phylogenies: assessing the performance of PhyML 3.0. Systematic Biology 59(3):307®321

5. Jiao Y, Chen D (2000) The diversity and distribution of goatfish (Mullidae) in Western Pacific. Journal of Ocean University of China 30(1):48ه56

6. Kalyaanamoorthy S, Minh BQ, Wong TKF, von Haeseler A, Jermiin LS (2017) ModelFinder: fast model selection for accurate phylogenetic estimates. Nature Methods 14(6):587\589

7. Minh BQ, Nguyen MAT, von Haeseler A (2013) Ultrafast approximation for phylogenetic bootstrap. Molecular Biology and Evolution 30(5):1188ه1195

8. Nelson JS, Grande TC, Wilson MVH (2016) Fishes of the world. Fifth edition. New Jersey 
9. Nguyen L-T, Schmidt HA, von Haeseler A, Minh BQ (2015) IQ-TREE: A fast and effective stochastic algorithm for estimating maximum-likelihood phylogenies. Molecular Biology and Evolution 32(1):268ه274

10. Pavlov DA, Emel'yanova NG (2018) Variation of freckled goatfish Upeneus tragula (Mullidae): Color morphs off Hon Thom (Gulf of Thailand, South China Sea). Journal of ichthyology 58(3):371ه381

11. Shan B, Liu Y, Yang C, Zhao Y, Zhang G, Wu Q, Sun D (2021) DNA barcoding of fish in Mischief reeffish diversity of a reef fish community from Nansha Islands. Frontiers in Marine Science 7

12. Sharifuzzaman SM, Rasid MH, Rubby IA, Debnath SC, Xing B, Chen G, Chowdhury MSN, Hossain MS (2021) DNA barcoding confirms a new record of flyingfish Cheilopogon spilonotopterus (Beloniformes: Exocoetidae) from the northern Bay of Bengal. Conservation Genetics Resources

13. Shen S (1993) Family Mullidae. In: Shen S (ed) Fishes of Taiwan. Department of Zoology, National Taiwan University, Taipei, pp 385§389

14. Uiblein F, Gledhill DC, Pavlov DA, Hoang TA, Shaheen S (2019) Three new goatfishes of the genus Upeneus (Mullidae) from the Indo-Pacific, with a redescription of colour patterns in U. margarethae. Zootaxa 4683(2):151ه196

15. Uiblein F, Gledhill DC, Peristiwady T (2017) Two new goatfishes of the genus Upeneus (Mullidae) from Australia and Indonesia. Zootaxa 4318(2):295区311

16. Uiblein F, Gouws G (2014) A new goatfish species of the genus Upeneus (Mullidae) based on molecular and morphological screening and subsequent taxonomic analysis. Marine Biology Research 10(7):655®681

17. Uiblein F, Heemstra PC (2010) A taxonomic review of the Western Indian Ocean goatfishes of the genus Upeneus (Family Mullidae), with descriptions of four new species. Smithiana Bulletin 11:35】 71

18. Uiblein F, Motomura $\mathrm{H}$ (2021) Three new goatfishes of the genus Upeneus from the Eastern Indian Ocean and Western Pacific, with an updated taxonomic account for U. itoui (Mullidae: japonicusspecies group). Zootaxa 4938(3):298囚324

19. Ward RD, Zemlak TS, Innes BH, Last PR, Hebert PDN (2005) DNA barcoding Australia' s fish species. Philosophical Transactions of the Royal Society B: Biological Sciences 360(1462):1847-1857

20. Yi M, Zhao C, Su X, Tao Y, Yan Y (2018) New record of Japanese snake blenny Xiphasia matsubarai (Perciformes: Blenniidae) from South China Sea. Journal of Oceanology and Limnology 36(4):1401区 1407

21. Zhang D, Gao F, Jakovlić I, Zou H, Zhang J, Li WX, Wang GT (2020) PhyloSuite: An integrated and scalable desktop platform for streamlined molecular sequence data management and evolutionary phylogenetics studies. Molecular Ecology Resources 20:348囚355

\section{Tables}


Table 1 Morphometric measurements and meristic counts of Upeneus spottocaudalis and Upeneus sundaicus (\% in SL, average value in parentheses) 
Upeneus sundaicus Upeneus spottocaudalis

\begin{tabular}{|c|c|c|}
\hline $\mathrm{n}$ & 13 & 24 \\
\hline SL & $100.3-146.5(120.5)$ & $87.9-122.7(105.4)$ \\
\hline \multicolumn{3}{|l|}{ in \% SL } \\
\hline Body depth at first dorsal-fin origin & 24.9-31.3 (27.9) & 24.3-28.2 (25.7) \\
\hline Body depth at anal-fin origin & $21.3-25.9(23.6)$ & $20.1-23.5(21.8)$ \\
\hline Half body depth at first dorsal-fin origin & $19.6-25.9(22.5)$ & $18.2-25.7(20.5)$ \\
\hline Half body depth at anal-fin origin & $15.7-20.5(17.1)$ & $13.9-23.2(15.9)$ \\
\hline Caudal-peduncle depth & $10.8-13.7(12.1)$ & $9.4-11.3(10.4)$ \\
\hline Caudal-peduncle width & $4.3-4.9(4.7)$ & $3.2-4.5(3.8)$ \\
\hline Maximum head depth & $22.8-28.9(25.1)$ & $22.5-27.9(24.2)$ \\
\hline Head depth through eye & $15.0-20.0(17.4)$ & $14.9-18(16.2)$ \\
\hline Suborbital depth & 8.2-12.8 (10.8) & $6.3-11.3(8.1)$ \\
\hline Interorbital length & $6.7-8.3(7.7)$ & $7.1-8.5(7.6)$ \\
\hline Head length & 22.3-29.2 (25.7) & 22.6-27.7 (25.7) \\
\hline Snout length & $6.7-9.7(8.4)$ & $5.2-9.4(7.6)$ \\
\hline Postorbital length & $9.0-12.6(10.7)$ & $9.5-11.5(10.4)$ \\
\hline Orbit length & $5.1-7.9(6.8)$ & $6.9-8.5(7.7)$ \\
\hline Orbit depth & $5.0-6.5(5.7)$ & $5.4-8.0(7)$ \\
\hline Upper-jaw length & 7.2-11.7 (9.2) & $6.5-10.0(8.2)$ \\
\hline Lower-jaw length & $5.1-9.1(7.3)$ & $5.7-9.3(7.1)$ \\
\hline Snout width & $6.4-8.8(7.9)$ & $5.6-9.1(8.1)$ \\
\hline Barbel length & 15.3-20.0 (17.5) & $15.0-19.0(16.6)$ \\
\hline Maximum barbel width & $0.8-1.3(1.0)$ & $0.9-1.2(1.0)$ \\
\hline First pre-dorsal length & $30.8-35.5(32.8)$ & $31.1-36.8(33.5)$ \\
\hline Second pre-dorsal length & $59.4-70.1(63.6)$ & $61.9-66.5(63.9)$ \\
\hline Interdorsal distance & 10.6-15.4 (13.0) & 11.5-18.4 (15.5) \\
\hline Caudal-peduncle length & 20.6-27.1 (23.3) & 19.2-29.1 (22.9) \\
\hline Pre-anal length & $62.1-70(65.5)$ & $63.5-72.8(66.2)$ \\
\hline
\end{tabular}




\begin{tabular}{|c|c|c|}
\hline Pre-pelvic length & $16.2-32.8(28.5)$ & $26.9-31.4(29.4)$ \\
\hline Pre-pectoral length & $24.4-30.4(27.3)$ & $25.5-32.9(27.4)$ \\
\hline Second dorsal-fin depth & $22.4-25.9(24.1)$ & $20.6-23.9(22.6)$ \\
\hline Pelvic-fin depth & $23.8-29.6(26.6)$ & $24.0-29.5(25.7)$ \\
\hline Pectoral-fin depth & $13.8-19(16.5)$ & $13.0-18.1(16.4)$ \\
\hline Length of first dorsal-fin base & $13.6-20.5(17.3)$ & $12.5-19.7(14.4)$ \\
\hline Length of second dorsal-fin base & $12.4-17.1(14.8)$ & $12.0-15.6(13.7)$ \\
\hline Caudal-fin length & $24.2-30(27.4)$ & $24.8-32.4(29.1)$ \\
\hline Length of anal-fin base & $10.0-10.7(10.3)$ & 7.7-11.9 (10.2) \\
\hline Anal-fin height & $6.9-10.3(9.0)$ & $6.4-16.4(9.9)$ \\
\hline Pelvic-fin length & $14.2-22.1(18.9)$ & $14.3-21.3(18.6)$ \\
\hline Pectoral-fin length & $18.6-23.3(20.3)$ & $16.6-22.1(19.9)$ \\
\hline Pectoral-fin width & $4.5-6.7(5.6)$ & $3.8-6.1(4.5)$ \\
\hline First dorsal-fin height & $19.8-27.1(23.7)$ & $17.6-21.7(19.6)$ \\
\hline Second dorsal-fin height & $14.2-16.5(15.2)$ & 15.9-17.1 (16.5) \\
\hline \multicolumn{3}{|l|}{ Meristic characters } \\
\hline Dorsal-fin spines & $\mathrm{VIII+9}$ & $\mathrm{VII}+9$ \\
\hline Anal-fin spines & $1-6$ & $\mathrm{I}-6$ \\
\hline Pelvic-fin spines & $1-5$ & $1-5$ \\
\hline Pectoral-fin spines & 14 & 14 \\
\hline Scales along lateral line & $28-31$ & $26-30$ \\
\hline Scales above lateral line & 2.5 & 2 \\
\hline Scales below lateral line & 4.5 & $3-4$ \\
\hline Total gill rakers & $4-6+13-15$ & $3-5+10-15$ \\
\hline
\end{tabular}

\section{Figures}




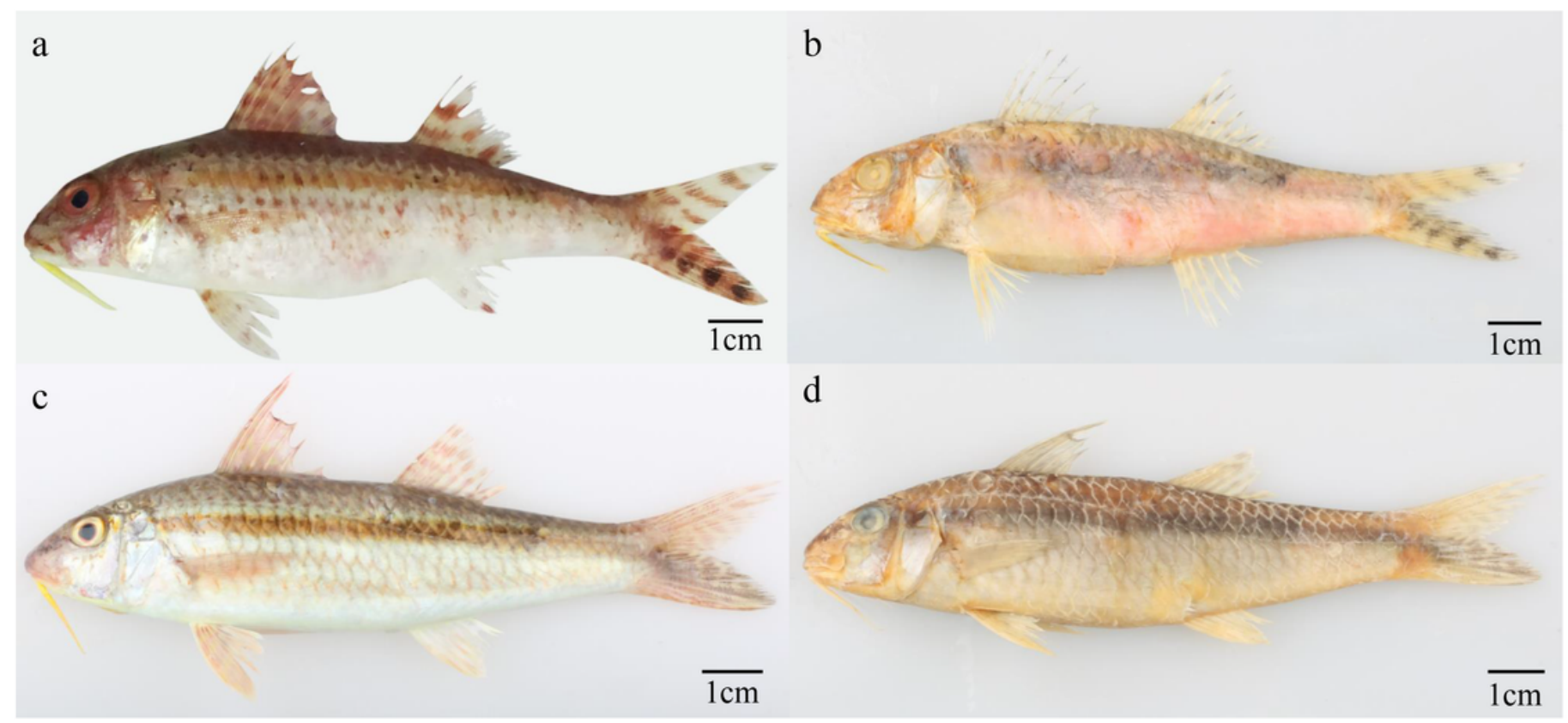

\section{Figure 1}

Upeneus spottocaudalis, (a) fresh specimens, MuSY001, 107.1mm SL, Sanya, China; (b) preserved specimens, MuHK003, 104.2mm SL, Haikou, China. Upeneus sundaicus, (c) fresh specimens, GOU104525, 106.9mm SL, Zhanjiang, China; (d) preserved specimens, GOU104525, 106.9mm SL, Zhanjiang, China 


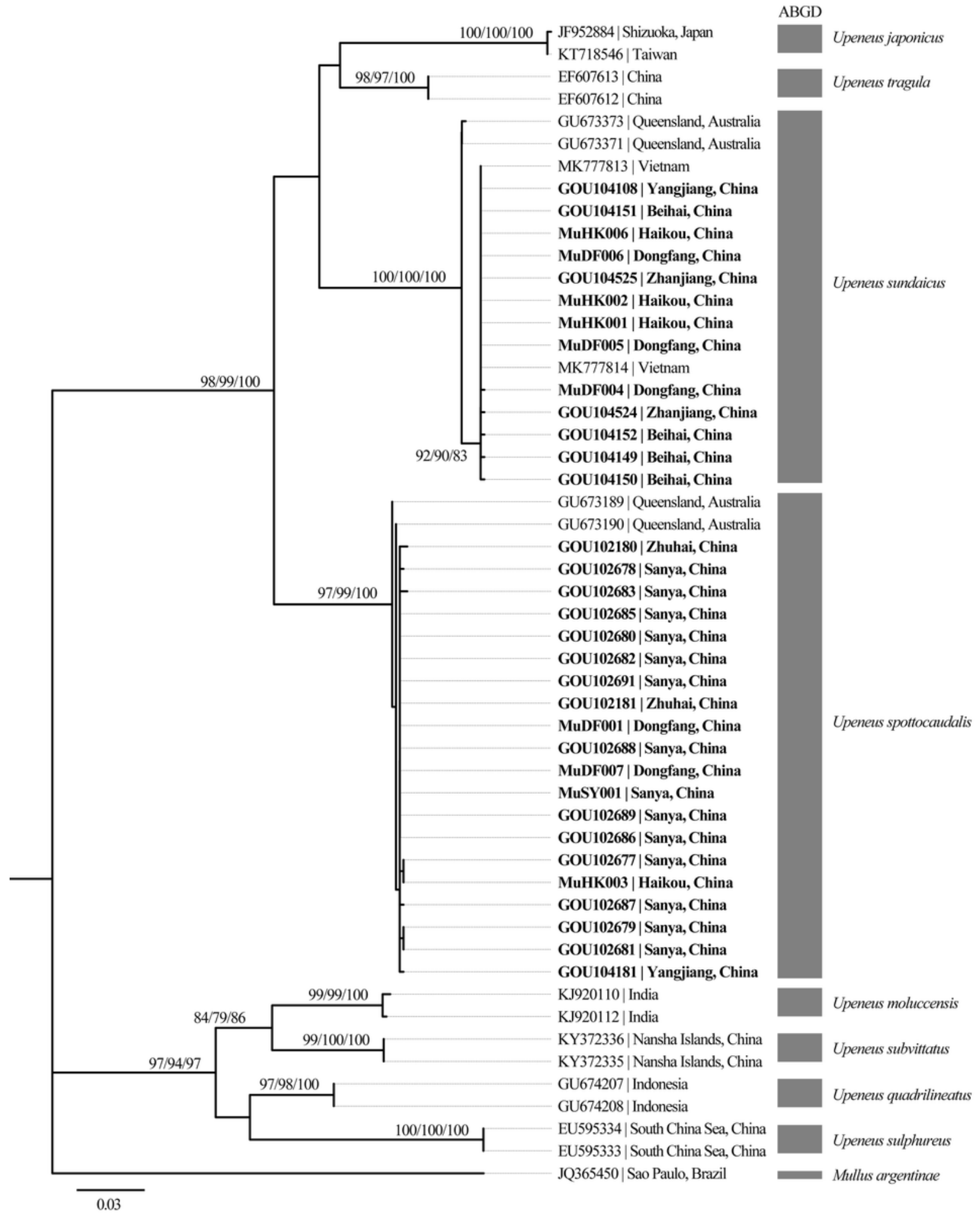

Figure 2

Maximum likelihood (ML) and neighbor-joining $(\mathrm{NJ})$ tree of Upeneus based on DNA sequences of the mitochondrial COI gene (blod fonts for this study). Numbers on the branch are SH-aLRT support (\%), and the bootstrap values for $\mathrm{ML}$ and $\mathrm{NJ}$ analyses. Only values above $70 \%$ are displayed. Gray rectangles for result of $A B G D$ analysis, and each rectangle represents single species 


\section{Supplementary Files}

This is a list of supplementary files associated with this preprint. Click to download.

- SupplementaryTable.docx 